Hai-Lin Chen, Jian-Jing Lan*, Yue Qin, Dong-Mei Yao, Yan-Ping Wang, Meng-Xi Li and Chuang Tan

\title{
The crystal structure of catena-poly[bis $\left(\mu_{2}-\right.$ 1,2-bis((1H-imidazol-1-yl)methyl)benzene- $\mathrm{K}^{2} \mathrm{~N}$ :N')-bis(nitrato-kO)copper(II)], $\mathrm{C}_{28} \mathrm{H}_{28} \mathrm{~N}_{10} \mathrm{O}_{6} \mathrm{Cu}$
}

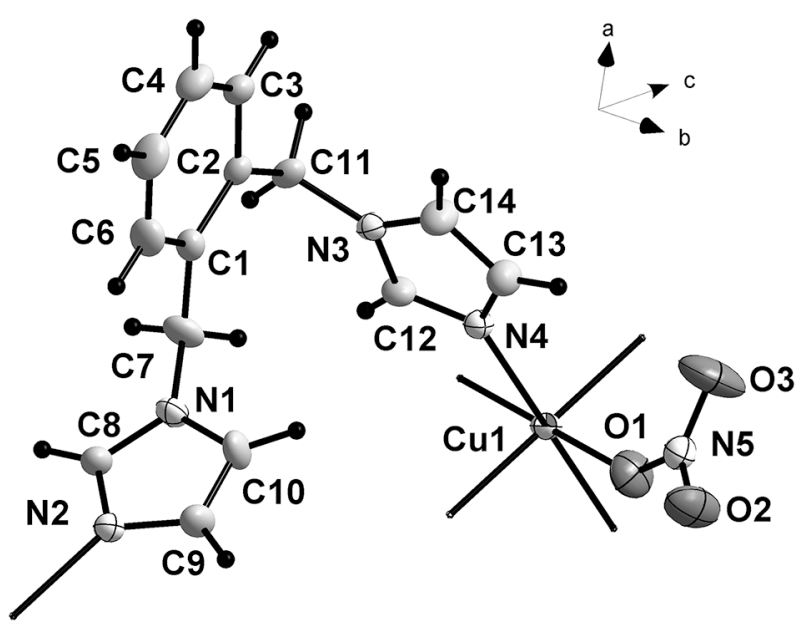

https://doi.org/10.1515/ncrs-2021-0135

Received April 8, 2021; accepted April 26, 2021; published online May 18, 2021

\section{Abstract}

$\mathrm{C}_{28} \mathrm{H}_{28} \mathrm{~N}_{10} \mathrm{O}_{6} \mathrm{Cu}$, triclinic, $P \overline{1}$ (no. 2), $a=8.6869(7) \AA$, $b=9.0094(6) \AA, c=9.5839(8) \AA$ A $\alpha=74.288(7)^{\circ}$, $\beta=87.672(9)^{\circ}, \gamma=76.110(7)^{\circ}, V=700.69(11) \AA^{3}, Z=1$, $R_{g t}(F)=0.0492, w R_{\text {ref }}\left(F^{2}\right)=0.0979, T=293(2) \mathrm{K}$.

\section{CCDC no.: 2080049}

Table 1 contains crystallographic data and Table 2 contains the list of the atoms including atomic coordinates and displacement parameters.

\section{Source of material}

A mixture of $\mathrm{Cu}\left(\mathrm{NO}_{3}\right)_{2} \cdot 3 \mathrm{H}_{2} \mathrm{O}(0.05 \mathrm{mmol}), 2,2$-bis $\left(\left(2^{\prime}\right.\right.$-carboxy[1,1'-biphenyl]-4-yl)methyl)isoindolin-2-ium chloride

*Corresponding author: Jian-Jing Lan, School of Chemical and Biological Engineering, Hechi University, Yizhou, Guangxi, 546300, China, E-mail: 170118546@qq.com

Hai-Lin Chen, Yue Qin, Dong-Mei Yao, Yan-Ping Wang, Meng-Xi Li and Chuang Tan, School of Chemical and Biological Engineering, Hechi University, Yizhou, Guangxi, 546300, China. https://orcid.org/ 0000-0001-9471-8109 (H. Chen)
Table 1: Data collection and handling.

\begin{tabular}{|c|c|}
\hline Crystal: & Purple block \\
\hline Size: & $0.34 \times 0.20 \times 0.15 \mathrm{~mm}$ \\
\hline Wavelength: & Mo $K \alpha$ radiation $(0.71073 \AA)$ \\
\hline$\mu$ : & $0.84 \mathrm{~mm}^{-1}$ \\
\hline Diffractometer, scan mode: & Xcalibur, $\omega$ \\
\hline$\theta_{\max }$, completeness: & $29.5^{\circ},>99 \%$ \\
\hline$N(h k l)_{\text {measured }}, N(h k l)_{\text {unique }}, R_{\text {int }}:$ & $5920,3203,0.035$ \\
\hline Criterion for $I_{\mathrm{obs}}, N\left(h k l_{\mathrm{gt}}\right.$ : & $I_{\text {obs }}>2 \sigma\left(I_{\text {obs }}\right), 2607$ \\
\hline$N(\text { param })_{\text {refined }}:$ & 205 \\
\hline Programs: & $\begin{array}{l}\text { CrysAlis }{ }^{P R O}[1], \text { SHELX }[2,3] \text {, } \\
\text { Diamond [4] }\end{array}$ \\
\hline
\end{tabular}

(0.05 mmol), 1,2-bis((1H-imidazol-1-yl)methyl)benzene (0.05 mmol), $1 H$-pyrazole (0.05 mmol), NaOH (0.2 mmol) and $5.5 \mathrm{~mL}$ of $\mathrm{DMF} / \mathrm{EtOH} / \mathrm{MeOH} / \mathrm{H}_{2} \mathrm{O}$ (1:1:2:1.5) was sealed in a $20 \mathrm{~mL}$ vial and heated at $358 \mathrm{~K}$ for 15 days. Purple block crystals were collected.

\section{Experimental details}

$\mathrm{H}$ atoms were placed in calculated positions and were included in the refinement in the riding model approximation, with $U_{\text {iso }}(\mathrm{H})$ set to $1.2 U_{\mathrm{eq}}(\mathrm{C})$.

\section{Comment}

In recent years, 1,2-bis((1H-imidazol-1-yl)methyl)benzene has been widely applied in the formation of many kinds of metal coordination complexes [5-10]. In this study it was used to prepare a new $\mathrm{Cu}^{2+}$ coordination polymer.

The asymmetric unit of the title structure has one 1,2-bis((1H-imidazol-1-yl)methyl)benzene ligand, one nitrate anion, one half of a $\mathrm{Cu}$ (II) cation. The nitrate ion is coordinated to the $\mathrm{Cu}(\mathrm{II})$ ion. $\mathrm{Cu} 1$ forms a distorted octahedral geometry, with four imidazole nitrogen atoms in the equatorial plane and two oxygen atoms of nitrate ions in axial positions. The Cu1-N2 and Cu1-N4 bond lengths 
Table 2: Fractional atomic coordinates and isotropic or equivalent isotropic displacement parameters $\left(\AA^{2}\right)$.

\begin{tabular}{lrrrr}
\hline Atom & $\boldsymbol{x}$ & $\boldsymbol{y}$ & $\boldsymbol{z}$ & $\boldsymbol{U}_{\text {iso }} / \boldsymbol{U}_{\text {eq }}$ \\
\hline CU1 & 0.000000 & 0.500000 & 1.000000 & $0.02377(14)$ \\
O1 & $0.0352(3)$ & $0.7872(3)$ & $0.9029(2)$ & $0.0436(6)$ \\
O2 & $0.0824(3)$ & $1.0169(3)$ & $0.8078(3)$ & $0.0552(7)$ \\
O3 & $0.2379(3)$ & $0.8481(3)$ & $0.9718(3)$ & $0.0702(8)$ \\
N1 & $0.2175(3)$ & $0.3420(3)$ & $0.4075(2)$ & $0.0264(5)$ \\
N2 & $0.0978(2)$ & $0.4657(3)$ & $0.1966(2)$ & $0.0244(5)$ \\
N3 & $0.3969(2)$ & $0.2327(2)$ & $0.8542(2)$ & $0.0219(5)$ \\
N4 & $0.2090(2)$ & $0.3952(3)$ & $0.9365(2)$ & $0.0227(5)$ \\
N5 & $0.1171(3)$ & $0.8839(3)$ & $0.8966(2)$ & $0.0283(5)$ \\
C1 & $0.4753(3)$ & $0.1961(3)$ & $0.5342(3)$ & $0.0244(6)$ \\
C2 & $0.5607(3)$ & $0.1336(3)$ & $0.6661(3)$ & $0.0210(5)$ \\
C3 & $0.7248(3)$ & $0.1084(3)$ & $0.6676(3)$ & $0.0266(6)$ \\
H3 & 0.781464 & 0.065099 & 0.755294 & $0.032^{*}$ \\
C4 & $0.8052(3)$ & $0.1470(3)$ & $0.5397(3)$ & $0.0342(7)$ \\
H4 & 0.915180 & 0.128954 & 0.541394 & $0.041^{*}$ \\
C5 & $0.7211(4)$ & $0.2119(4)$ & $0.4109(3)$ & $0.0371(7)$ \\
H5 & 0.774146 & 0.240384 & 0.325162 & $0.044^{*}$ \\
C6 & $0.5580(4)$ & $0.2355(3)$ & $0.4073(3)$ & $0.0334(7)$ \\
H6 & 0.502664 & 0.278310 & 0.318923 & $0.040^{*}$ \\
C7 & $0.2975(3)$ & $0.2148(3)$ & $0.5295(3)$ & $0.0314(7)$ \\
H7A & 0.276010 & 0.115715 & 0.524112 & $0.038^{*}$ \\
H7B & 0.253997 & 0.235957 & 0.618900 & $0.038^{*}$ \\
C8 & $0.1560(3)$ & $0.3263(3)$ & $0.2877(3)$ & $0.0276(6)$ \\
H8 & 0.154588 & 0.229540 & 0.271104 & $0.033^{*}$ \\
C9 & $0.1236(3)$ & $0.5760(3)$ & $0.2617(3)$ & $0.0323(7)$ \\
H9 & 0.094762 & 0.685487 & 0.222273 & $0.039^{*}$ \\
C10 & $0.1973(4)$ & $0.5010(3)$ & $0.3917(3)$ & $0.0355(7)$ \\
H10 & 0.228363 & 0.548149 & 0.457533 & $0.043^{*}$ \\
C11 & $0.4808(3)$ & $0.0913(3)$ & $0.8101(3)$ & $0.0255(6)$ \\
H11A & 0.406033 & 0.029134 & 0.802674 & $0.031^{*}$ \\
H11B & 0.560257 & 0.026333 & 0.883930 & $0.031^{*}$ \\
C12 & $0.2476(3)$ & $0.2596(3)$ & $0.9012(3)$ & $0.0252(6)$ \\
H12 & 0.180521 & 0.191683 & 0.907874 & $0.030^{*}$ \\
C13 & $0.3397(3)$ & $0.4571(3)$ & $0.9123(3)$ & $0.0310(7)$ \\
\hline & 0.347101 & 0.552487 & 0.928392 & $0.037^{*}$ \\
H14 & $0.4567(3)$ & $0.3579(3)$ & $0.8614(3)$ & $0.0331(7)$ \\
0.557777 & 0.372017 & 0.836168 & $0.040^{*}$ \\
\hline
\end{tabular}

(2.014(2) and 1.989(2) A, respectively) in the equatorial plane are shorter than the Cu1-O1 bond length ( $2.590 \AA)$ of the axis. A one dimensional polynuclear chain of the complex is formed by the connection of the ligand to two neighboring $\mathrm{Cu}(\mathrm{II})$ ions (see the Figure). The lattice constants of the title complex were almost the same as the reported copper complex [10].

Author contributions: All the authors have accepted responsibility for the entire content of this submitted manuscript and approved submission.

Research funding: This work was financially supported by the Foundation of Hechi University (No. 2020XJYB004 and XJ2018GKQ014), Guangxi Natural Science Foundation of China (No. 2020GXNSFBA297138 and 2018GXNSFBA294004).

Conflict of interest statement: The authors declare no conflicts of interest regarding this article.

\section{References}

1. Rigaku. CrysAlis ${ }^{P R O}$; Rigaku Corporation: Yarnton, Oxfordshire, England, 2015.

2. Sheldrick G. M. SHELXTL - integrated space-group and crystalstructure determination. Acta Crystallogr. 2015, A71, 3-8.

3. Sheldrick G. M. Crystal structure refinement with SHELXL. Acta Crystallogr. 2015, C71, 3-8.

4. Brandenburg K. DIAMOND. Visual Crystal Structure Information System. Ver. 3.2; Crystal Impact: Bonn, Germany, 2012.

5. Cai Y. Crystal structure of catena-poly-\{aqua- $\left[\mu_{2}-1,2-b i s((1 H\right.$ imidazol-1-yl) methyl)benzene- $\left.\kappa^{2} N: N\right]-\left[\mu_{2}-4,4^{\prime}\right.$ (dimethylsilanediyl)dibenzato- $\left.\kappa^{3} O, O^{\prime}: O^{\prime}\right]$ nickel(II)\}, $\mathrm{C}_{30} \mathrm{H}_{30} \mathrm{~N}_{4} \mathrm{NiO}_{5} \mathrm{Si}$. Z. Kristallogr. NCS 2017, 232, 121-123.

6. Lian Z., Zhao N., Liu P., An C., Wang A., Yang F. Crystal structures and investigation of the third-order nonlinear optical properties of four coordination polymers by using the Z-scan technique. CrystEngComm 2018, 20, 5833-5843.

7. Liu K., Deng L., Zhang Y., Jiao S., Geng Y., Wang L. Coordination behaviour of bis-imidazole and various carboxylate ligands towards $\mathrm{Zn}$ (II) and Cd(II) ions: synthesis, structure, and photoluminescence study. Crystals 2018, 8, 236.

8. Zhang Y., Li H., Wang Z., Liu K., Jiao S., Liu Y., Xiao Z., Xu J., Wang L. Coordination preference of 1,2-bis(( $1 \mathrm{H}$-imidazole-1-yl)methyl) benzene and different carboxylate ligands with transition metal ions directed by weak interactions. J. Solid State Chem. 2019, 275 , 124-130.

9. Liu R.-Q., Zhao N., Yang F.-X., Wang A.-R., Liu P., An C.-X., Lian Z.-X. Enhanced third-order nonlinear optical properties of three 2D coordination polymers based on bis(imidazole) ligands and dicarboxylic ligands. Polyhedron 2016, 111, 16-25.

10. Semerci F., Yeşilel O. Z., Yüksel F. Self-assembly of three new metal organic coordination networks based on 1,2-bis(imidazol1yl-methyl)benzene. Polyhedron 2015, 102, 1-7. 